\title{
Cinética de produção de levedura seca em leito de jorro
}

\author{
Ana P. T. Rochaa ${ }^{1}$ Odelsia L. S. Alsina ${ }^{1}$, Vimário S. Silva ${ }^{1}$ \& Flávio L. H. da Silva ${ }^{1}$
}

\section{RESUMO}

Estudou-se neste trabalho, a cinética de produção durante a secagem em um secador de leito de jorro convencional com inertes, trabalhando-se com alimentação intermitente de levedura, com umidade inicial de 70\% em base úmida. Fez-se um planejamento fatorial $2^{2}$ mais configuração estrela com 3 experimentos no ponto central, totalizando 11 experimentos, objetivando-se o estudo da influência da concentração de levedura e velocidade do ar na entrada sobre a cinética de produção de levedura seca. A cinética se mostrou crescente e praticamente linear em todos os experimentos. Esta análise permitiu a identificação das condições ideais de operação do secador com relação à velocidade de operação e de quantidade de levedura a ser alimentada para obtenção de um produto de qualidade para utilização como complemento protéico na alimentação de animais.

Palavras-chave: secagem, armazenamento, Saccharomyces cerevisiae

\section{Production kinetics of dry yeast in spouted bed}

\begin{abstract}
In this study the production kinetics are studied during drying in a conventional spouted bed drier, with inert particles, working at intermittent feeding of yeast, with initial moisture content of $70 \%$ (wet basis). In order to study the influence of the yeast concentration and the input air speed on the production kinetics of dry yeast, a series of 11 experiments according to a factorial design $2^{2}$ plus a star configuration, with 3 experiments in the central point, was done. It was found that the increasing kinetics was practically linear in all the experiments. From this analysis, optimal operational conditions were found for the drier input air velocity and amount of yeast to be loaded. The attainment of a quality product to be used as a protein complement for animal feeding was also considered.
\end{abstract}

Key words: spouted bed drier, storage, Saccharomyces cerevisiae 


\section{INTRODUÇÃO}

As leveduras fazem parte dos mais diversos produtos que podem ser utilizados como suplementos protéicos convencionais na ração animal. Esses microrganismos possuem elevada velocidade de crescimento, possibilidade de serem cultivados em diversos tipos de substratos e possuem, ainda, um alto teor de proteínas e vitamina B (Rocha, 2002).

O Brasil é o maior produtor mundial de álcool etílico via processo fermentativo, utilizando-se da levedura como o microrganismo agente da fermentação. É prática comum nas indústrias de produção de álcool etílico no Brasil, a sangria do creme de levedura, que consiste em se retirar parte do creme do processo de centrifugação (Silva, 1998); desta forma, a Saccharomyces cerevisiae é uma fonte excedente do processo de fermentação alcoólica que pode ser utilizada como suplemento protéico para ração animal (Santin, 1996).

A levedura pode ser usada como fonte de proteínas, vitaminas e palatabilizante nas formulações de ração animal. Alguns autores têm estudado a secagem de leveduras (Saccharomyces cerevisiae) com o objetivo de utilizá-las como complemento protéico na alimentação de animais, dentre os quais se pode citar Butolo (1996) que relata sobre o uso de levedura para este fim destacando as suas propriedades e o custo relativo, se comparado a outras fontes de nutrientes. Araújo et al. (2005) avaliaram o processo de enriquecimento protéico da palma forrageira (Opuntia ficus-indica Mill) tal como Oliveira et al. (2005) em referência ao processo de enriquecimento protéico da casca do abacaxi (Ananas comosus L. Mer), utilizando a Saccharomyces cerevisiae em meio semi-sólido para uso na alimentação de animais, durante os períodos de seca. Silva et al. (2006) avaliaram o desempenho de secadores fluidodinamicamente ativos para secagem de leveduras em que os resultados mostram que as perdas de carga registradas no leito fluidizado foram maiores que no leito de jorro na presença de leveduras em qualquer proporção de levedura/inerte.

Para que a levedura seja comercializada pelos produtores de ração animal, é conveniente que obedeça as especificações exigidas pelo mercado quanto aos aspectos de cor, granulometria, teor de proteína e teor de umidade, para que se evite o aparecimento de bolores e empedramento do produto (Silva, 2004). Com o exposto, conclui-se que a operação de secagem se torna indispensável, uma vez que coloca a biomassa sob a forma física, o que facilita o armazenamento, o transporte e, conseqüentemente, a comercialização.

O leito de jorro com partículas inertes se apresenta como alternativa interessante porque, aliado às suas conhecidas características de altas taxas de transferência de calor e massa, permite que se obtenha um produto com granulometria fina e uniforme, com tempos de contato curtos, o que contribui para a qualidade do produto.

A cinética de produção é importante, haja vista que avalia a eficiência do processo de secagem de leveduras em leito de jorro, definindo condições ótimas de operação do secador. O presente trabalho tem, como objetivo, o estudo da cinética de produção verificando a influência da vazão do ar na entrada do secador e percentual de levedura alimentada sobre a produção de leveduras secas, para posterior uso como complemento protéico para alimentação animal. Utilizou-se, no presente trabalho, a metodologia da superfície de resposta mediante um planejamento fatorial $2^{2}+$ configuração estrela no estudo da cinética de secagem da levedura Saccharomyces cerevisiae.

\section{MATERIAL E MÉTODOS}

\section{Matéria-prima}

A matéria-prima utilizada na alimentação do secador foi levedura do gênero Saccharomyces cerevisiae compacta do tipo comercial, com umidade média de $70 \%$ em base úmida e teor de proteína bruta de 50\% em base seca; a levedura era peneirada através de malhas de $0,991 \mathrm{~mm}$ de abertura com o objetivo de diminuir o tamanho dos aglomerados. Como material inerte foram utilizadas partículas de poliestireno com diâmetro da esfera de igual volume de $0,33 \mathrm{~cm}$, densidade de $1,045 \mathrm{~g} \mathrm{~cm}^{-3}$, esfericidade igual a 0,87 e porosidade do leito fixo de 0,411. Segundo Almeida (1991) este material é aprovado para uso em alimentos.

\section{Equipamento}

O secador em leito de jorro mostrado na Figura 1, é formado de uma base cônica de acrílico, com ângulo interno de $60^{\circ}$, acoplada a uma coluna cilíndrica também em acrílico, com diâmetro interno de 0,103 m, 0,253 m de altura e diâmetro interno da base cônica de 0,028 m; na parte superior da coluna é conectado um ciclone, com a finalidade de separar e coletar a levedura seca; o secador possui orifícios que permitem tomadas de temperatura e pressão. A alimentação da levedura é feita por gravidade, na parte superior da coluna.

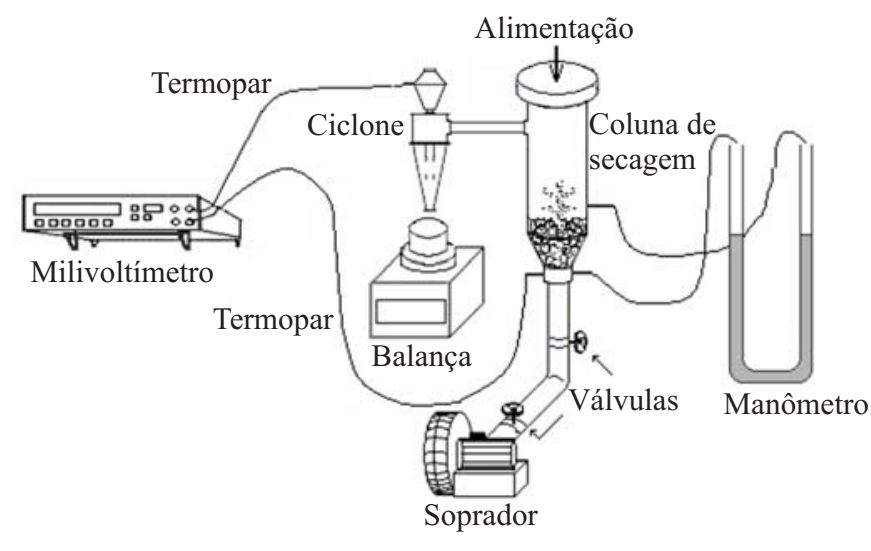

Figura 1. Esquema do leito de jorro

\section{Condições de operação}

A faixa de concentração de leveduras empregada neste trabalho foi obtida com base no estudo da fluidodinâmica do leito de jorro e se encontra entre 1,2 a $6,8 \%$ da massa de inertes. Quanto às velocidades de trabalho, foram fixadas em $1,1,1,2$ e 1,3 da velocidade de jorro mínimo, que é de $0,1676 \pm 0,0086 \mathrm{~m} \mathrm{~s}^{-1}$. A quantidade de inerte foi fixada em 
0,250 kg para todos os testes; a alimentação de levedura foi realizada de modo intermitente pela parte superior do secador, mantendo-se o equipamento em funcionamento e o percentual de levedura se refere à quantidade adicionada em cada alimentação, relativa à massa de partículas inertes. Em todos os experimentos, a temperatura do ar de secagem foi de $43 \pm 2{ }^{\circ} \mathrm{C}$ e a umidade relativa de aproximadamente $65 \%$ (Rocha, 2002).

\section{Planejamento experimental}

Com a finalidade de analisar a influência da concentração de levedura e velocidade do ar na entrada sobre a cinética de produção de levedura seca, utilizou-se a metodologia de planejamento experimental fatorial e análise de superfície de resposta, mediante um planejamento fatorial $2^{2}$ mais configuração estrela, com a realização de 3 experimentos no ponto central resultando, desta forma, em 11 experimentos.

A Tabela 1 mostra os valores do percentual de levedura alimentada, a cada 20 min, no secador, com relação à massa de inerte, e a velocidade do ar na entrada da coluna de secagem com os níveis dos fatores utilizados nas corridas experimentais.

Tabela 1. Valores reais e codificados das variáveis do planejamento fatorial $2^{2}+$ configuração estrela

\begin{tabular}{lccccc}
\hline \multirow{2}{*}{ Variáveis } & \multicolumn{5}{c}{ Níveis } \\
\cline { 2 - 6 } & $\mathbf{- 1 , 4 1 4}$ & -1 & $\mathbf{0}$ & $\mathbf{+ 1}$ & $\mathbf{+ 1 , 4 1 4}$ \\
Percentual de Levedura (\%) & 1,2 & 2,0 & 4,0 & 6,0 & 6,8 \\
Velocidade do $\mathrm{Ar}\left(\mathrm{m} \mathrm{s}^{-1}\right)$ & 0,185 & 0,199 & 0,213 & 0,227 & 0,241 \\
\hline
\end{tabular}

\section{Cinética de produção}

Avaliou-se a cinética de produção de pó em todos os ensaios de secagem e se fizeram 5 alimentações em intervalos regulares de $20 \mathrm{~min}$, resultando no tempo total de 1 h $40 \mathrm{~min}$ para cada experimento. O acompanhamento da produção de levedura seca foi realizado por meio de pesagem em uma balança Mettler PC 440, localizada abaixo do ciclone. As condições de operação do secador, referentes à velocidade de secagem e percentual de levedura alimentada, foram determinadas a partir da matriz de planejamento experimental.

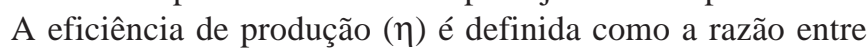
a massa do pó coletado no ciclone após o período de secagem $\left(\mathrm{M}_{\mathrm{LS}}\right)$ e a massa total alimentada no secador $\left(\mathrm{M}_{\mathrm{L}}\right)$; sendo assim, pode-se escrever:

$$
\eta(\%)=\frac{M_{L S} \cdot\left(1-X_{(L S)}\right)}{M_{L} \cdot\left(1-X_{(L)}\right)} \cdot 100
$$

donde $\mathrm{X}_{(\mathrm{LS})}$ é a umidade da levedura coletada e $\mathrm{X}_{(\mathrm{L})}$ é a umidade da levedura alimentada no secador, ambas em base úmida.

\section{RESULTADOS E DISCUSSÃO}

As cinéticas de produção de levedura seca são mostradas na Figura 2A, através das curvas relacionando massa acu- mulativa de levedura seca, produzida em função do tempo. Na Figura 2B se observa a eficiência de produção de levedura com o tempo, para as diferentes condições operacionais mantidas durante a realização dos experimentos. As condições operacionais dos experimentos 1 a 11 estão listadas na Tabela 2. A discussão dos resultados será com relação à produção uniforme de levedura seca e a sua evolução ao longo das sucessivas alimentações, como mostra a Figura 2A. Observa-se, neste gráfico, a linearidade da massa acumulativa de levedura com o tempo, indicando que as taxas de produção de pó são praticamente constantes, salvo um pequeno desvio das curvas nos experimentos 9 e 11.

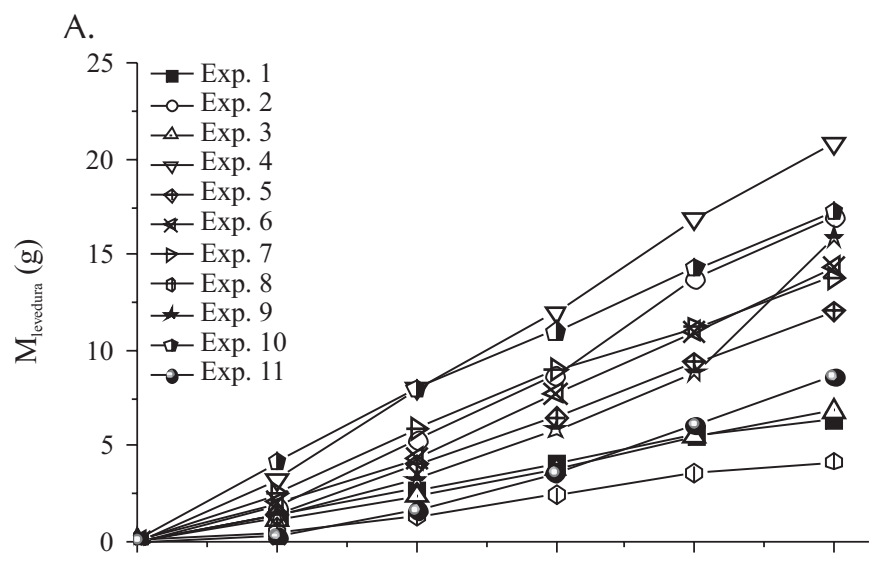

B.

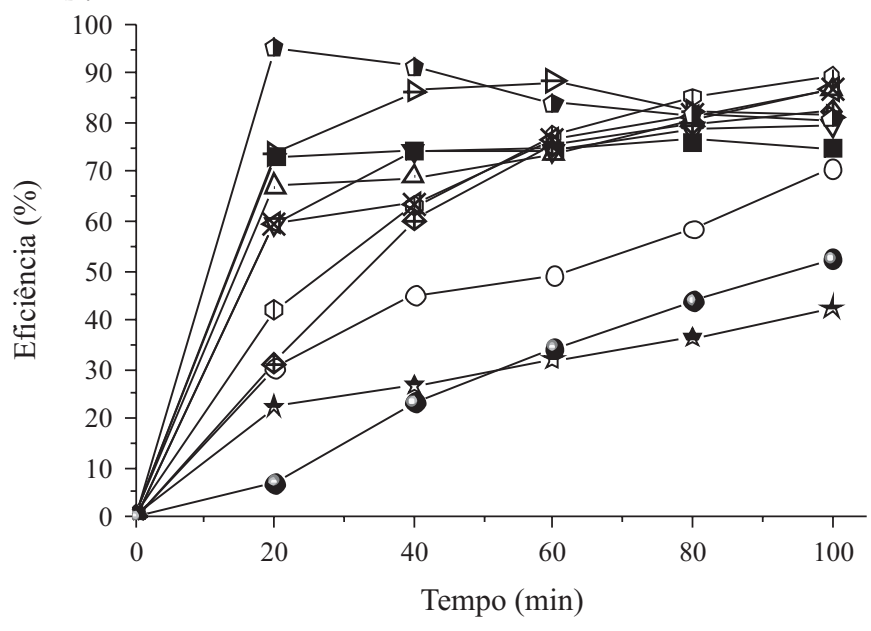

Figura 2. Massa de levedura coletada em função do tempo (A) e a eficiência de produção de levedura em função do tempo (B)

A Figura 2B ilustra que as eficiências de produção de levedura durante a maioria dos ensaios são aproximadamente constantes a partir da terceira alimentação; a partir deste ponto, o leito passa a operar em estado estacionário com uma produção uniforme de levedura seca, o que confirma, mais uma vez, que as taxas de produção são constantes nas condições aqui estudadas. Ainda neste gráfico se constata novamente o comportamento diferenciado dos ensaios 9 e 11, nas quais não se observa a uniformidade da eficiência de produção de levedura até a $5^{\text {a }}$ 
alimentação mas fica evidenciado, nos experimentos 9 e 11 que, embora não constante até a $5^{\mathrm{a}}$ alimentação, a eficiência de produção apresenta tendência de se tornar uniforme com a continuidade do processo, após sucessivas alimentações. Esta diferença de comportamento pode estar associada à alta concentração de leveduras no leito no experimento 9, enquanto no experimento 11 foi utilizada a menor velocidade do ar de entrada. Em ambos os casos, alta concentração de leveduras ou baixa velocidade do ar, maior tempo será necessário para a estabilização do regime de produção com eficiência constante no sistema. Na Tabela 2 se apresentam os valores de eficiências calculadas após a $5^{\mathrm{a}}$ alimentação, $\eta\left(5^{\mathrm{a}}\right)$ para os 11 experimentos e, pelos resultados obtidos, se mostra que a eficiência apresenta, em geral, tendência a aumentar com o aumento da velocidade do ar e a diminuir com o aumento da proporção de levedura. Esses resultados eram previstos já que uma maior velocidade do ar aumenta a transferência de calor e massa incrementando, assim, a taxa de secagem. Elevadas velocidades do ar propiciam também o arraste das partículas de levedura seca a serem coletadas no ciclone, porém com elevadas proporções de levedura a eficiência tende a diminuir, embora a produção absoluta possa aumentar, em virtude das maiores exigências de desempenho pelo aumento da carga no secador.

Os dados de cinética de produção de levedura seca foram ajustados, mediante regressão linear, à Eq. 2.

$$
\mathrm{R}=\mathrm{Kt}
$$

em que: $\mathrm{R}$ é a massa total recolhida no ciclone ao longo do tempo e $\mathrm{K}$, a constante cinética.

Encontram-se na Tabela 2, os resultados do ajuste linear aos dados experimentais de massa acumulativa em função do tempo, confirmando as taxas constantes de produção de levedura seca. Os menores coeficientes de correlação dos experimentos 9 e 11, obtidos a partir do ajuste do modelo linear aos dados desses ensaios, decorrem de instabilidades no leito, o primeiro devido ao elevado percentual de levedura alimentada e o segundo em conseqüência da baixa velocidade do ar na entrada do secador, como já referido.

\section{Superfície de resposta - taxa de produção}

Sabe-se que a taxa de produção de levedura seca é dada pela derivada da Eq. 2 em cada um dos experimentos realizados, de modo que a taxa de produção em gramas de levedura por unidade de tempo é igual à constante cinética $\mathrm{K}$. Utilizando-se o planejamento fatorial $2^{2}+$ configuração estrela e três repetições no ponto central, proposto neste trabalho, levantou-se a influência das combinações das variáveis concentração de leveduras e velocidade do ar sobre a taxa de produção de levedura seca indicada na Tabela 2. O planejamento foi analisado através do software Statistica, para realizar a regressão não linear dos dados experimentais. O modelo quadrático codificado obtido para a taxa de produção em função das variáveis estudadas, é mostrado na Eq. 3. Os coeficientes estatisticamente significativos (dois primeiros) e os desvios padrão para o modelo estão na equação abaixo para 95\% de confiança.

$$
\begin{aligned}
\mathrm{K}= & (0,1366 \pm 0,015)+\left[0,051 \pm 0,089\left(\mathrm{M}_{\mathrm{L}} / \mathrm{M}_{\mathrm{I}}\right)\right]+ \\
& (0,019 \pm 0,089 \mathrm{U})-\left[0,015 \pm 0,011\left(\mathrm{M}_{\mathrm{L}} / \mathrm{M}_{\mathrm{I}}\right)^{2}\right]+ \\
& \left(0,0013 \pm 0,011 \mathrm{U}^{2}\right)+\left[0,0079 \pm 0,013\left(\mathrm{M}_{\mathrm{L}} / \mathrm{M}_{\mathrm{I}}\right) \mathrm{U}\right]
\end{aligned}
$$

Tem-se, na Tabela 3, os resultados da análise de variância (ANOVA) para a taxa de produção. O coeficiente de correlação que explica a qualidade do ajuste entre as respostas observadas e os valores determinados pelo modelo ajustado, é de 0,944; com relação ao teste F, que é utilizado para investigar se o modelo explica uma quantidade significativa da variação nos valores experimentais, pode-se considerar que o modelo obtido é estatisticamente significativo com 95\% de confiança, já que a razão entre o valor de F calculado foi maior que o F tabelado; entretanto, o modelo não pode ser considerado preditivo uma vez que o $\mathrm{F}$ calculado e o $\mathrm{F}$ tabelado é menor que 4, conforme Barros Neto et al. (2001).

\begin{tabular}{|c|c|c|c|c|c|c|c|c|}
\hline Experimento & $\begin{array}{c}\text { ML/MI } \\
(\%)\end{array}$ & $\begin{array}{c}U \\
\left(\mathrm{~m} \mathrm{~s}^{-1}\right)\end{array}$ & \multicolumn{2}{|c|}{ Regressão linear Eq. (2) K(g min-1) } & $\begin{array}{c}\eta_{(5 a)} \\
(\%)\end{array}$ & $\begin{array}{c}\Delta P \\
\left(N / m^{2}\right)\end{array}$ & $\begin{array}{c}\text { Proteína } \\
\text { (bs \%) }\end{array}$ & $\begin{array}{c}\text { Umid } \\
(\%)\end{array}$ \\
\hline 1 & 2 & 0,199 & 0,065 & 0,997 & 75 & 610,30 & 51,82 & - \\
\hline 2 & 6 & 0,199 & 0,178 & 0,992 & 70 & 524,70 & 50,09 & 23,7 \\
\hline 3 & 2 & 0,227 & 0,069 & 0,998 & 87 & 610,30 & 50,95 & 11,65 \\
\hline 4 & 6 & 0,227 & 0,213 & 0,999 & 80 & 524,70 & 51,82 & 16,25 \\
\hline 5 & 4 & 0,213 & 0,123 & 0,992 & 85 & 531,70 & 51,82 & 18,64 \\
\hline 7 & 4 & 0,213 & 0,140 & 0,998 & 82 & 531,70 & 51,82 & 11,65 \\
\hline 8 & 1,2 & 0,213 & 0,045 & 0,993 & 90 & 610,30 & 51,82 & 12,59 \\
\hline 9 & 6,8 & 0,213 & 0,149 & 0,955 & 40 & 524,70 & 51,82 & 16,20 \\
\hline 10 & 4 & 0,241 & 0,171 & 0,998 & 82 & 531,70 & 52,68 & 31,34 \\
\hline 11 & 4 & 0,185 & 0,089 & 0,972 & 50 & 531,70 & 52,68 & 13,13 \\
\hline
\end{tabular}

Tabela 3. Análise de variância para a taxa de produção

\begin{tabular}{lc}
\hline \% variância explicada & 89,19 \\
Coeficiente de correlação & 0,944 \\
Teste F (calculado) & 8,81 \\
F tabelado para 95\% de confiança & 5,05 \\
F calculado/F tabelado & 1,74 \\
\hline
\end{tabular}

Tabela 2. Resultados da cinética de produção de levedura seca 
Analisando-se o parâmetro F calculado na verificação da validade estatística do modelo ajustado, vê-se que o valor de F calculado pela regressão dos dados experimentais é maior que o valor de $\mathrm{F}$ tabelado para uma distribuição de referência com 95\% de confiança, mostrando que o modelo apresenta uma quantidade de variação devida ao modelo ajustado superior à variação não explicada, indicando que o modelo ajustado representa bem os valores experimentais (Barros Neto et al., 2001; Box \& Draper, 1987); então, pode-se utilizar a Eq. 3 para gerar a superfície de resposta para a taxa de produção, enquanto a Figura 3 ilustra a superfície de resposta que apresenta os efeitos do percentual de levedura e velocidade do ar sobre a taxa de produção.

Observando-se os efeitos das variáveis de entrada sobre a taxa de produção, Figura 3, verifica-se que as variáveis de entrada apresentam efeitos positivos sobre a resposta, ou seja, aumentando-se os níveis de -1 para +1 , a taxa de produção aumenta, sendo o efeito de $1^{\text {a }}$ ordem da variável percentual de levedura mais significativo que a variável velocidade do ar, apesar dos termos quadráticos não serem significativos. Devido ao termo quadrático negativo do fator concentração de levedura e às interações velocidade-concentração, deve existir um valor ótimo das variáveis de entrada que maximize a taxa de produção. Isto pode ser observado na curvatura da superfície da Figura 3 na qual, para valores de percentagem de levedura em torno de $6 \%$ e velocidade do ar de $0,220 \mathrm{~m} \mathrm{~s}^{-1}$ se obtém taxa de produção superior a $0,2 \mathrm{~g} \mathrm{~min}^{-1}$ de levedura seca.

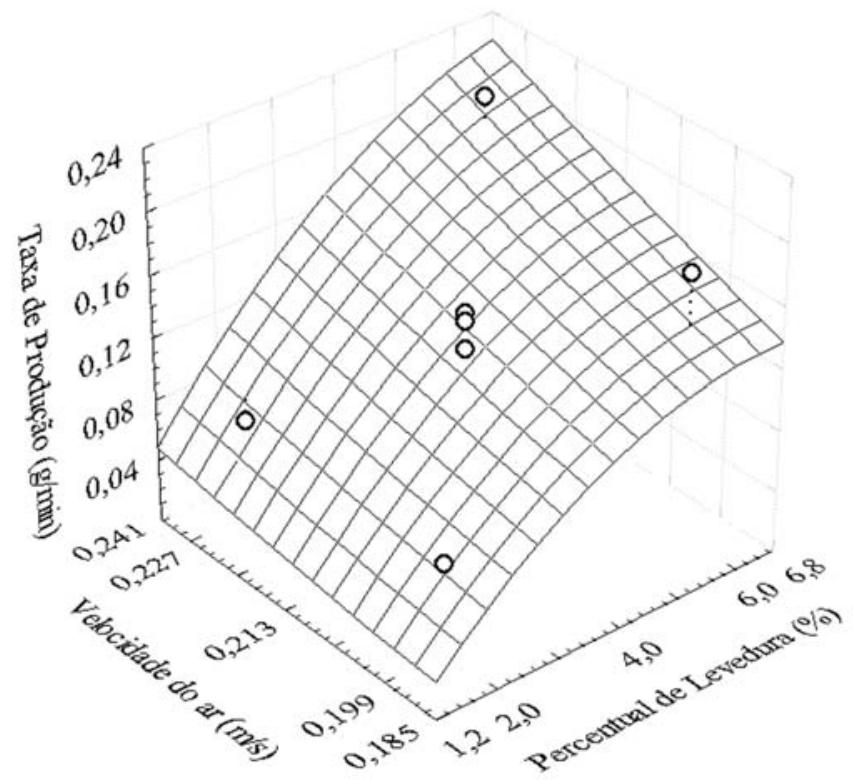

Figura 3. Superfície de resposta para taxa de produção

Com relação à qualidade do produto obtido, a análise será feita em termos da umidade final e teor de proteínas, variáveis que dependem das condições de operação, especialmente o conteúdo de umidade mas, considerando-se os valores médios encontrados nos diversos experimentos, pode-se dizer que, em geral, são compatíveis com os en- contrados na literatura. Os resultados das médias dos teores de umidade e proteínas totais das células de Saccharomyces cerevisiae secas encontradas neste trabalho, são mostrados na Tabela 4, comparativamente com os valores obtidos por outros autores.

Tabela 4. Qualidade do produto comparado a trabalhos de outros autores

\begin{tabular}{lcc}
\hline & Proteínas & Umidade \\
\cline { 2 - 3 } & \multicolumn{2}{c}{$\%$} \\
Rheinboldt et al. (1987) & $32-38$ & 8 \\
Santin (1996) & 50 & - \\
Oliveira et al. (1996) & $25,99-27,24$ & $7,77-11,21$ \\
Nicácio (2002) & $12,09-57,81$ & 12 \\
Presente trabalho & $50,09-52,68$ & $11,19-31,34$ \\
\hline
\end{tabular}

As composições médias de proteínas citadas por Rheinboldt et al. (1987) variaram de 32 a 38\%, quando se utilizou um secador spray dryer, com levedura industrial ( $S$. cerevisiae) e teor de umidade final de $8 \%$. Oliveira et al. (1996), trabalhando também com secador spray dryer e levedura $S$. cerevisiae entre temperaturas de operação de 73 a $140{ }^{\circ} \mathrm{C}$, obtiveram teores de umidade e proteínas de 7,77 a $11,21 \%$ e 25,99 a $27,24 \%$, respectivamente, valores esses obtidos sob diversas condições operacionais; os autores atribuíram o aumento da umidade e a diminuição das proteínas totais ao aumento da vazão de alimentação. Este resultado não foi constatado neste trabalho, visto que em todas as condições experimentais estudadas se obteve praticamente o mesmo valor para as proteínas. Valores semelhantes aos aqui apresentados foram obtidos por Santin (1996), trabalhando com secagem em estufa e temperaturas de 55 a $120^{\circ} \mathrm{C}$, que encontrou um teor de proteínas em torno de $50 \%$ em todos os ensaios.

Nicácio (2002) obteve resultados referentes à umidade (12\%) e teor de proteínas $(12,09$ a 57,56\%) de estudos realizados com secagem de leveduras em estufa. Como utilizou diversas faixas de temperatura, para efeito de comparação com os dados aqui apresentados, pode-se tomar o valor do teor de proteínas a 40 e $55^{\circ} \mathrm{C}$, que é de 48,7 e 48,4\%, respectivamente; esses resultados são inferiores aos encontrados neste estudo, o que pode ser justificado pelo tempo total do processo de secagem. No caso da secagem em estufa, o tempo total foi de $300 \mathrm{~min}$, enquanto no leito de jorro aqui estudado, todo o processo ocorreu em 100 min (tempo 3 vezes menor) e a levedura seca começa a ser coletada a partir dos 2 min iniciais de secagem; conclui-se, então, que a variável tempo tem influência no processo, ou seja, a desnaturação das proteínas ocorre com o binômio tempo e temperatura, sendo a desnaturação maior em tempos mais longos. Nicácio (2002) concluiu que, em geral, um aumento de temperatura requer um tempo menor de secagem e, portanto, maior teor de proteínas e melhor qualidade do produto.

Os resultados obtidos em escala laboratorial apontam para boas perspectivas de aplicação industrial como suplemento alimentar, em função de não ter sido observada perdas no percentual de proteína bruta do produto. Apesar da elevada relação massa de inerte/massa de levedura, as perdas de 
carga, na operação de jorro estável, são inferiores a 400 Pa. Entretanto, estudos complementares relativos à ampliação de escala se fazem necessários para uma melhor previsão das capacidades de produção.

\section{CONCLUSÕES}

1. Os resultados da cinética de produção de levedura seca mostraram que nas condições estudadas neste trabalho, a taxa de produção é uniforme.

2. As eficiências de produção de levedura durante a maioria dos ensaios são aproximadamente constantes a partir da terceira alimentação, com exceção dos ensaios 2, 9 e 11, que não apresentaram uniformidade até a $5^{\text {a }}$ alimentação.

3. As eficiências encontradas variaram entre 40 a $90 \%$, dependendo das condições operacionais.

4. O modelo quadrático codificado obtido para a taxa de produção em função das variáveis estudadas, é estatisticamente significativo com 95\% de confiança.

5. A taxa de produção frente às variáveis de entrada apresenta aumento com valor superior a $0,200 \mathrm{~g} \mathrm{~min}^{-1}$ para valores de percentagem de levedura maior que $6 \%$ e velocidade do ar maior que $0,220 \mathrm{~m} \mathrm{~s}^{-1}$.

6. As médias dos teores de umidade e proteínas totais encontradas, são superiores quando comparadas com os valores obtidos por outros autores, estando as proteínas dentro dos padrões exigidos pela legislação de no mínimo 25\%.

\section{LITERATURA CITADA}

Almeida, M. M. Desidratação de polpa de umbu. Campina Grande: UFPB, 1991. 90p. Relatório de Iniciação Científica.

Araújo, L. F.; Conrado, L. S.; Perazzo Neto, A.; Silva, F. L. H. Equilíbrio higroscópico da palma forrageira: Relação com a umidade ótima para fermentação sólida. Revista Brasileira de Engenharia Agrícola e Ambiental, Campina Grande, v.9, n.3, p.379-384, 2005.
Barros Neto, B.; Scarmínio, J. S.; Bruns, R. E. Planejamento e otimização de experimentos. 3.ed. Campinas: UNICAMP, 2001. 300p.

Box, G. E.; Draper, N. R. Empirical model building and response surfaces. New York: Wiley, 1987. 654p.

Butolo, J. E. Uso da biomassa de levedura em alimentação animal: propriedades, custo relativo a outras fontes de nutrientes. In: Workshop - Produção de Biomassa de Levedura: Utilização em alimentação animal, 1996, Campinas. Anais... Campinas: ITAL 1996. p.70-89.

Nicácio, S. Estudo da cinética da secagem de leveduras para uso como fonte protéica na ração animal. Campina Grande: UFCG, 2002. Dissertação Mestrado

Oliveira, C. A.; Liebsch, A. E.; Gimenes, M. L. Características de leveduras secas obtidas em spray dryer. In: Congresso Brasileiro de Sistemas Particulados, 24,1996, Uberlândia. Anais... Uberlândia: UFU, 1996. p.259-264.

Oliveira, M. M.; Campos, A. R. N.; Gouveia, J. P. G.; Silva, F. L. H. Isotermas de sorção do resíduo agroindustrial de casca do abacaxi (Ananas comosus L. Mer). Revista Brasileira de Engenharia Agrícola e Ambiental, Campina Grande, v.9, n.4, p.565-569, 2005.

Rheinboldt, R. H. H.; Leimer, K. H.; Rossell, C. E. V. Sangria e secagem de levedura - Processo CTC., São Paulo: COPERSUCAR, 1987. p.12. Boletim Técnico

Rocha, A. P. T. Estudo do desempenho de um leito de jorro convencional para secagem de leveduras. Campina Grande: UFCG, 2002. 156p. Dissertação Mestrado

Santin, A. P. Estudo da secagem da inativação de leveduras (Saccharomyces cerevisiae). Florianópolis: UFSC, 1996. 150p. Dissertação Mestrado

Silva, F. L. H. Modelagem, simulação e controle de fermentação alcoólica contínua extrativa. Campinas: UNICAMP, 1998. 162p. Tese Doutorado

Silva, V. S. Secagem de leveduras - Estudo comparativo do desempenho dos secadores em leito de jorro e leito fluidizado. Campina Grande: UFCG, 2004. 156p. Tese Doutorado

Silva, V. S.; Silva, F. L. H.; Alsina, O. L. S.; Rocha, A. P. T. Secagem de leveduras em leitos fluidodinamicamente ativos: avaliação do desempenho. In: Congresso Brasileiro de Engenharia Química, 16, 2006, Santos, Anais... Santos: USP/Lorena, p.259-264, 2006. 